\title{
Development and Evaluation of Novel PET Tracers for Imaging Cannabinoid Receptor Type 2 in Brain
}

\author{
Roger Slavik§a, Daniel Bieria, Stjepko Čermaka, Adrienne Müllera, Stefanie D. Krämerª, \\ Markus Weber ${ }^{b}$, Roger Schiblia, Simon M. Ametamey ${ }^{\star a}$, and Linjing Mu*c
}

§SCS-DSM Award for best poster presentation

\begin{abstract}
The cannabinoid receptor type 2 (CB2) has a very low expression level in brain tissue under basal conditions, but it is up-regulated in diverse pathological conditions. Two promising lead structures from the literature, $N$-((3S,5S,7S)-adamantan-1-yl)-8-methoxy-4-oxo-1-pentyl-1,4-dihydroquinoline-3-carboxamide and 8-butoxy- $N$-(2-fluoro-2-phenylethyl)-7-methoxy-2-oxo-1,2-dihydroquinoline-3-carboxamide - designated KD2 and KP23, respectively - were evaluated as potential PET ligands for imaging CB2. Both KD2 and KP23 were synthesized and labeled with carbon-11. In vitro autoradiographic studies on rodent spleen tissues showed that $\left[{ }^{11} \mathrm{C}\right] \mathrm{KD} 2$ exhibits superior properties. A pilot study using $\left[{ }^{11} \mathrm{C}\right] \mathrm{KD} 2$ on human post mortem ALS spinal cord slices indicated high CB2 expression level and specific binding, a very exciting finding if considering the future diagnostic application of CB2 ligands and their utility in therapy monitoring. In vivo blocking studies in rats with $\left[{ }^{11} \mathrm{C}\right] \mathrm{KD} 2$ showed also high specific uptake in spleen tissue. Although the protein-bound fraction is relatively high, KD2 or KD2 derivatives could be very useful tools for the non-invasive investigation of $C B 2$ levels under various neuroinflammatory conditions.
\end{abstract}

Keywords: Autoradiography · Cannabinoid receptor type 2 ligand · Neuroinflammation . Positron emission tomography · Radiolabeling

\section{Introduction}

Cannabinoid receptor types 1 (CB1) and 2 (CB2) were discovered about 30 years ago as $\mathrm{G}$ protein-coupled receptors containing seven transmembrane spanning domains. CB1 is expressed throughout the body, but mainly in brain regions (cerebellum, basal ganglia, hippocampus, and neocortex). CB2 is predominantly expressed on cells related to the immune system (spleen, lymphocytes) and also on keratinocytes. The presence of CB2

\footnotetext{
${ }^{*}$ Correspondence: Dr. L. Muc

Tel.: +41442559687

E-mail: linjing.mu@usz.ch

Prof. Dr. S. M. Ametamey ${ }^{a}$

Tel.: +41446337463

E-mail: simon.ametamey@pharma.ethz.ch

aETH Zürich, Institute of Pharmaceutical Sciences

Vladimir-Prelog-Weg 4

$\mathrm{CH}-8093$ Zürich

bMuskelzentrum/ALS clinic

Kantonsspital St. Gallen

$\mathrm{CH}-9007$ St. Gallen

'Department of Nuclear Medicine

University Hospital Zürich

$\mathrm{CH}-8091$ Zürich
}

in the central nervous system has been controversially discussed in literature since 1996. ${ }^{11]}$ Today CB2 is generally accepted to be present in brain tissues, although in very low concentrations.

However, under neuroinflammatory conditions, a CB2 level increase is observed. For instance in the brain of Alzheimer patients where activated microglia cluster at $\beta$-amyloid plaques. ${ }^{[2-5]}$ CB2 increase is also reported for the rat chronic lesion model of Huntington's disease, especially in the striatum. ${ }^{[6]}$ Furthermore, both hypoxia-ischemia and middle cerebral artery occlusion induced an up-regulation in the expression of CB2 in proliferating microglia in rat brain. ${ }^{7]}$ Increased CB2 levels were also reported in post mortem spinal cord of human patients of Amyotrophic Lateral Sclerosis (ALS) and corresponding mouse models and Multiple Sclerosis. ${ }^{4,8]}$

A large number of structurally diverse CB2 ligands have been synthesized and characterized in the past decade. ${ }^{9]}$ Among all these classes of CB2 ligands, 2-oxoquinoline and 4-quinolone-3carboxamide derivatives appear to be the most efficient inverse agonists, with high binding affinity and selectivity towards CB2. Currently, there are no PET (positron emission tomography) ligands for imaging
CB2 expression in humans. A suitable PET radioligand for imaging $\mathrm{CB} 2$ would be an invaluable research tool to explore the role of $\mathrm{CB} 2$ receptor expression in peripheral and/or central inflammatory disorders.

Herein, we report the in vitro/in vivo evaluation of two oxo-quinoline derivatives, designated $\left[{ }^{11} \mathrm{C}\right] \mathrm{KD} 2$ and $\left[{ }^{11} \mathrm{C}\right] \mathrm{KP} 23$, as potential radiotracers for imaging $\mathrm{CB} 2$ receptor by PET.

\section{Synthesis and Radiolabeling}

\subsection{Synthesis of KD2}

The synthesis of the reference compound, KD2, followed synthetic pathways already described.[10] In brief, the quinoline structure $\mathbf{2}$ was prepared via the Gould-Jacobs reaction as outlined in Scheme 1 by reacting anisidine with diethyl 2-(ethoxymethylene)malonate and subsequent benzannulation at high temperature. $\mathrm{N}$-alkylation with 1-bromopentane followed by hydrolysis of the ethyl ester gave the free quinoline acid 4, which was coupled to aminoadamantane using HBTU as the coupling reagent to yield KD2. Phenolic precursor compound 5 for radiolabeling was synthesized from the reference compound by demethylation using boron tribromide. 


\subsection{Synthesis of KP23}

The synthesis of the non-radioactive reference compound, KP23, was accomplished based on the modified procedure described by Turkman et al..$^{[1]}$ as outlined in Scheme 2. Briefly, compound 7 was obtained by aromatic nitration of 3-hydroxy-4-methoxybenzaldehyde (6) with nitric acid. O-alkylation with 1-bromobutane afforded intermediate $\mathbf{8}$. Reduction using iron powder followed by reaction in situ with dimethyl malonate yielded compound 9. Hydrolysis under basic conditions to the free acid $\mathbf{1 0}$ and amide bond formation using 2-fluoro-2phenylethanamine free base led to the final reference compound KP23. The phenolic precursor $\mathbf{1 1}$ for radiolabeling was directly synthesized from KP23 by demethylation using lithium chloride.

\subsection{Radiolabeling Procedure}

The phenolic precursor $\mathbf{5}$ or $\mathbf{1 1}$, was reacted with $\left[{ }^{11} \mathrm{C}\right]$-methyl iodide to afford $\left[{ }^{11} \mathrm{C}\right] \mathrm{KD} 2$ or $\left[{ }^{11} \mathrm{C}\right] \mathrm{KP} 23$, respectively (Scheme 3). Both tracers were obtained in $99 \%$ radiochemical purity after semiHPLC purification in yields of 2-5 GBq. The total radiolabeling time was around 40 min after $\left[{ }^{11} \mathrm{C}\right] \mathrm{CO}_{2}$ delivery from the cyclotron. Specific activity was high and ranged from 80 to $350 \mathrm{GBq} / \mu \mathrm{mol}$ at the end of synthesis.

\section{3. in vitro/in vivo Evaluation}

\subsection{Autoradiography Experiments}

To confirm specificity of binding of the radiotracers, rat and mouse spleens known to have a high physiological expression of CB2 were investigated in autoradiography experiments (Fig. 1). Specific binding of $\left[{ }^{11} \mathrm{C}\right] \mathrm{KD} 2$ and $\left[{ }^{11} \mathrm{C}\right] \mathrm{KP} 23$ was determined in blocking experiments (B1, B2) using the CB2 specific partial agonist GW405833 in 5000-fold excess.

Although high in vitro specific binding was observed for both radiotracers, $\left[{ }^{11} \mathrm{C}\right]$ $\mathrm{KD} 2$ showed superior properties and has greater potential to become a successful PET tracer. Consequently, we selected $\left[{ }^{11} \mathrm{C}\right] \mathrm{KD} 2$ for further evaluation in vitro and in vivo.

In a preliminary autoradiographic study, we investigated whether $\left[{ }^{11} \mathrm{C}\right] \mathrm{KD} 2$ binds to human post mortem ALS spinal cord slices, as literature reports suggest CB2 overexpression in the spinal cord of ALS patients. ${ }^{[12-14]}$ Fig. 2 confirms not only the presence of CB2 but also specific binding of $\left[{ }^{11} \mathrm{C}\right] \mathrm{KD} 2$. These are encouraging results towards non-invasive imaging of $\mathrm{CB} 2$ in ALS patients.

To exclude KD2 as a substrate for efflux transporter P-gp within the blood brain barrier, the permeation of $\left[{ }^{11} \mathrm{C}\right] \mathrm{KD} 2$ across

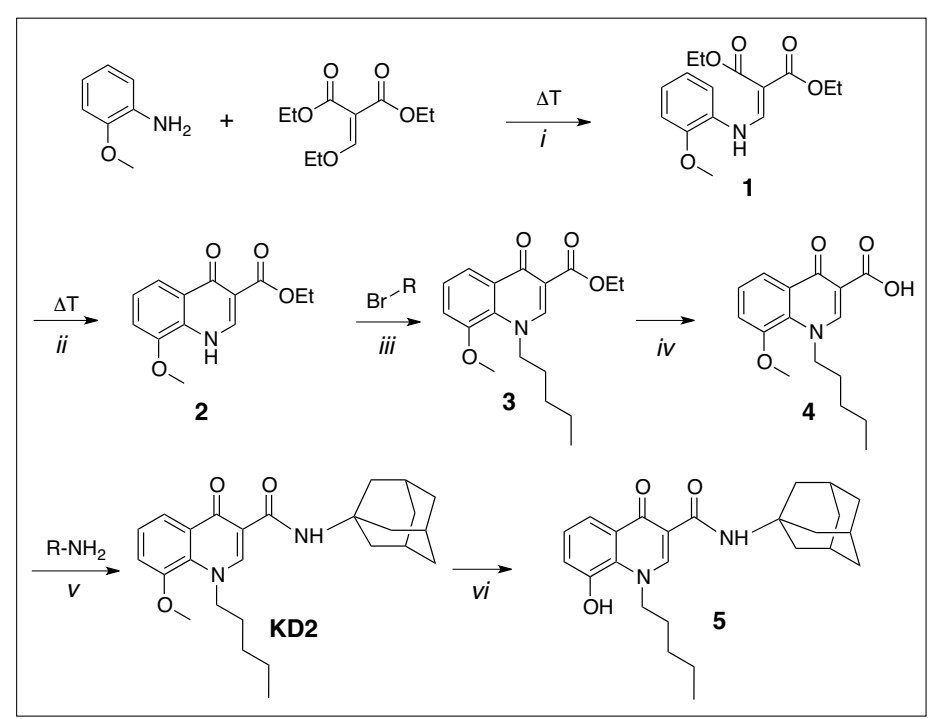

Scheme 1. Synthesis of KD2: (i) $110^{\circ} \mathrm{C}$ for $1 \mathrm{~h}, 88 \%$,

(ii) diphenylether, $250{ }^{\circ} \mathrm{C}$ for $1 \mathrm{~h}, 70 \%$, (iii) $\mathrm{DMF}, \mathrm{K}_{2} \mathrm{CO}_{3}$ $90{ }^{\circ} \mathrm{C}$ for $4 \mathrm{~h}, 95 \%$, (iv) $\mathrm{NaOH} 10 \%$, reflux for $3.5 \mathrm{~h}, 94 \%$, (v) DIPEA, HBTU in DMF, RT for $4 \mathrm{~h}$, quant., (vi) $\mathrm{BBr}_{3}$ in DCM, RT for $18 \mathrm{~h}$, $87 \%$.

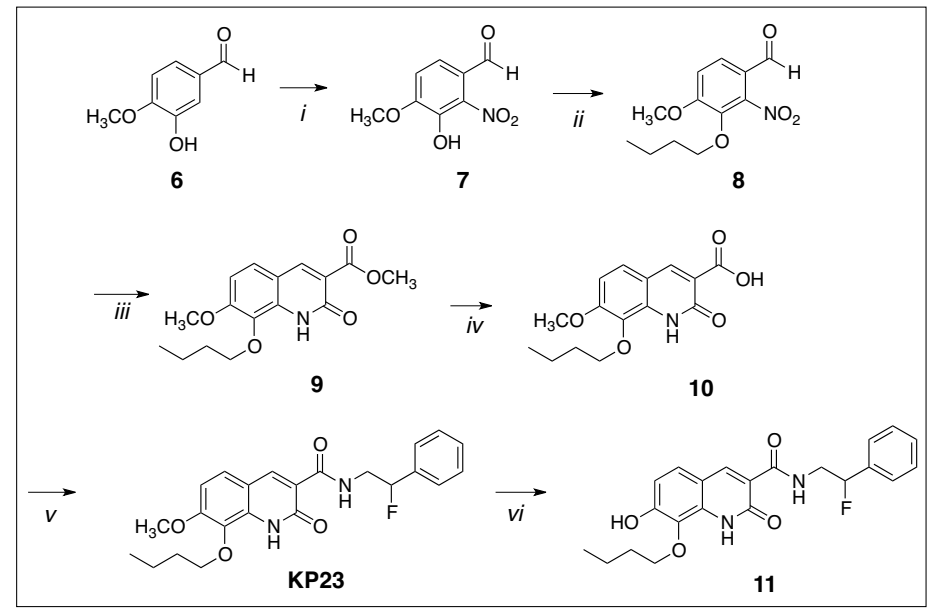

Scheme 2. Synthesis of KP23: (i) $\mathrm{HNO}_{3}$ in EtOAc, $2{ }^{\circ} \mathrm{C}$ for $2 \mathrm{~h}, 30 \%$, (ii) $\mathrm{K}_{2} \mathrm{CO}_{3}$ in DMF, $80^{\circ}$ for $16 \mathrm{~h}, 89 \%$, (iii) (a) piperidine, $\mathrm{AcOH}$ in toluene, reflux for $4 \mathrm{~h}$, (b) $\mathrm{AcOH}, \mathrm{Fe}, 100^{\circ} \mathrm{C}$ for 2 h, 34\%, (iv) $2 \mathrm{M}$ $\mathrm{KOH}$ in EtOH, RT for $6 \mathrm{~h}, 96 \%$, (v) DIPEA, HBTU in DMF, RT for $8 \mathrm{~h}, 46 \%$, (vi) LiCl in DMF, reflux for $4 \mathrm{~h}$, $72 \%$.

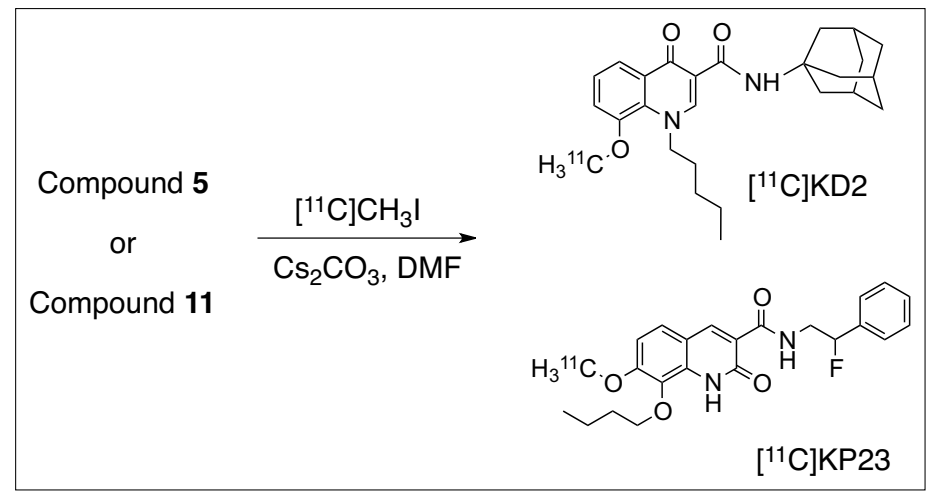

Scheme 3.

Radiosynthetic scheme towards $\left[{ }^{11} \mathrm{C}\right] \mathrm{KD} 2$ and $\left[{ }^{11} \mathrm{C}\right] \mathrm{KP} 23$.

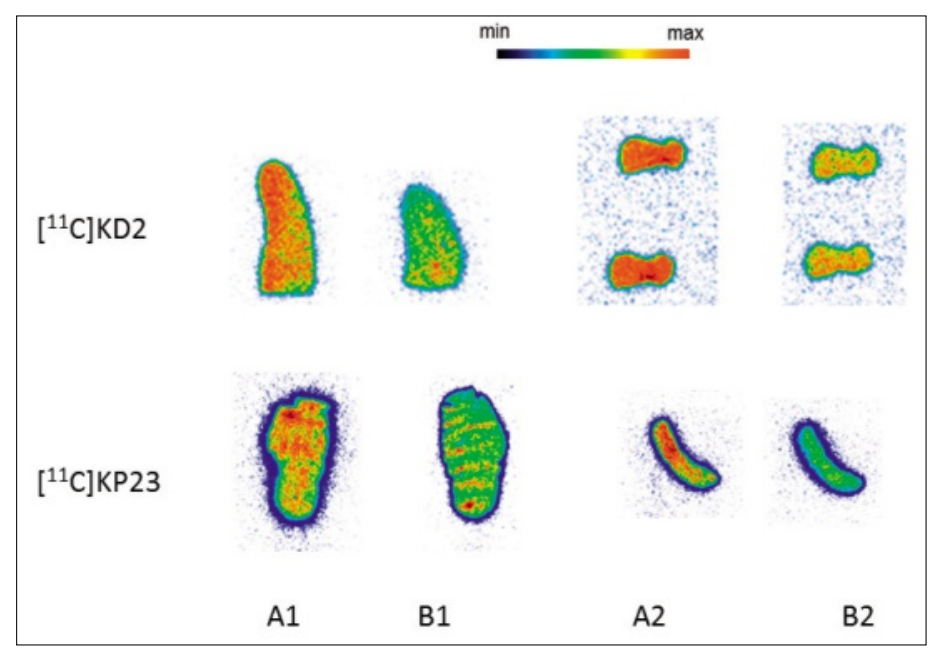

Fig. 1. A) $0.6 \mathrm{nM}$ $\left[{ }^{11} \mathrm{C}\right] \mathrm{KD} 2$ or $\left[{ }^{11} \mathrm{C}\right] \mathrm{KP} 23$ on rat (A1) and mouse (A2) spleen. B) Blocking with $5 \mu \mathrm{M}$ GW405833 on rat (B1) and mouse (B2) spleen. 


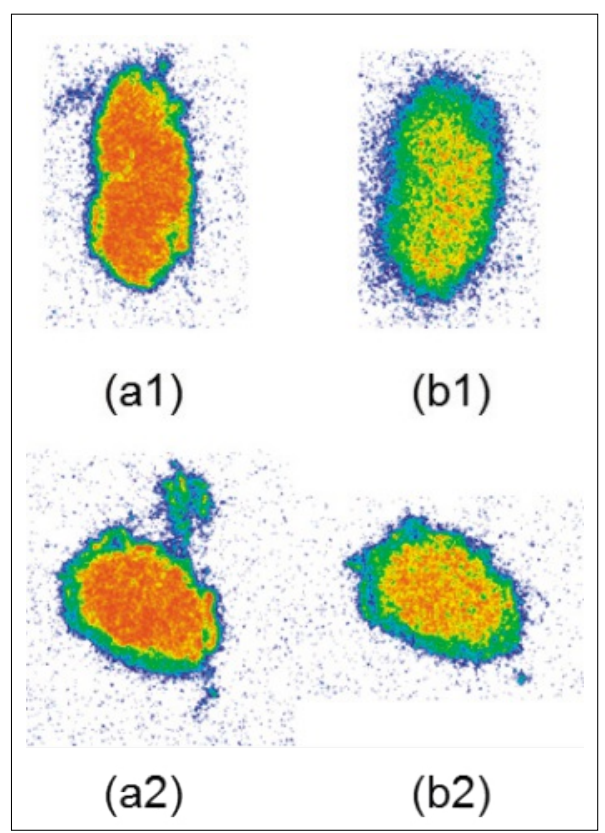

Fig. 2. In vitro autoradiography with slices from cervical spinal cord from two ALS patients. Incubation with $0.2 \mathrm{nM}\left[{ }^{11} \mathrm{C}\right] \mathrm{KD} 2$ in the absence (a) and presence (b) of $1 \mu \mathrm{M}$ GW405833.

MDCK cells transfected with human P-gp was investigated. The respective ratio for $\left[{ }^{11} \mathrm{C}\right] \mathrm{KD} 2$ of the transport basal to apical and apical to basal, respectively, was 0.5 , indicating no net efflux transport by P-gp.

Lipophilicity $(\log \mathrm{D})$ as an important physicochemical attribute for a CNS penetrating compound was determined by the shake-flask method in octanol/buffer at $\mathrm{pH} 7.4 .{ }^{[15]}$ The $\log \mathrm{D}$ value of $\left[{ }^{11} \mathrm{C}\right] \mathrm{KD} 2$ was found to be $3.29 \pm 0.04(n=6)$, and suggested that $\left[{ }^{11} \mathrm{C}\right] \mathrm{KD} 2$ would be a good blood-brain barrier penetrant.

The free fraction of $\left[{ }^{11} \mathrm{C}\right] \mathrm{KD} 2$ in human plasma was determined in a protein binding assay displaying a free fraction $f_{u}$ of 0.001 and in $4 \%$ BSA 0.017 . These findings were confirmed in an equilibrium dialysis experiment. The low free fraction is probably a consequence of the relatively high lipophilicity of $\left[{ }^{11} \mathrm{C}\right] \mathrm{KD} 2$. Increase of free fraction could be subject of future optimization.

\section{2 in vivo PET studies}

PET scans with Wistar rats showed high accumulation of $\left[{ }^{11} \mathrm{C}\right] \mathrm{KD} 2$ in liver, spleen and intestine. The accumulation in spleen was displaced by injection of the CB2 specific partial agonist GW405833 $(1.5 \mathrm{mg} / \mathrm{kg})$, indicating in vivo specific binding (Fig. 3). As expected, radioactivity in the brain was significantly lower than in the periphery (data not shown). Uptake in pons and cerebellum was higher than in hippocampus and caudate/putamen, in agreement with the expression pattern of $\mathrm{CB} 2$ in the rat brain. ${ }^{[16-18]}$

We are currently investigating the utility of $\left[{ }^{11} \mathrm{C}\right] \mathrm{KD} 2$ in mouse models of

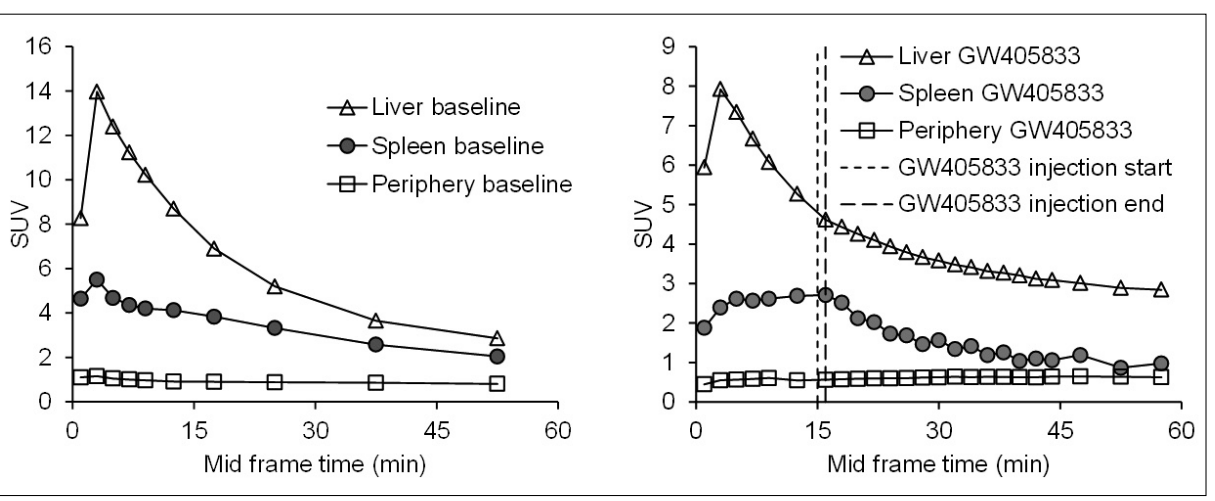

Fig. 3. Time activity curves of $\left[{ }^{11} \mathrm{C}\right] \mathrm{KD} 2$ from an in vivo displacement PET study. CB2 selective GW4058233 was injected i.v. from 15 to $16 \mathrm{~min}$ (dashed lines) after injection of $20 \mathrm{MBq}\left[{ }^{11} \mathrm{C}\right] \mathrm{KD} 2$.

neuroinflammation where $\mathrm{CB} 2$ receptors are upregulated, e.g. the lipopolysaccharide LPS mouse model as described by Qin et al. ${ }^{[19,20]}$

\section{Conclusion}

In the process of developing a suitable CNS radiotracer for imaging $\mathrm{CB} 2$ receptors we evaluated the potential of two lead compounds KD2 and KP23. We have established the syntheses of non-radioactive reference compounds using modified synthetic routes based on literature procedures. A robust and reliable radiosynthetic procedure for both novel $\mathrm{CB} 2$ radiotracers, $\left[{ }^{11} \mathrm{C}\right] \mathrm{KD} 2$ and $\left[{ }^{11} \mathrm{C}\right] \mathrm{KP} 23$, was established and afforded products with high specific activity, high radiochemical yields and excellent radiochemical purity of $\geq 99 \%$. In vitro autoradiography of both radiotracers on rodent spleen tissues and post mortem ALS spinal cord slices indicated specific binding to $\mathrm{CB} 2$. The results from the pilot study using human post mortem ALS spinal cord tissue sections showing high CB2 expression level are very exciting if one considers the future diagnostic application of CB2 ligands and their utility in therapy monitoring. Specific uptake into spleen tissue was also observed in dynamic PET studies using Wistar rats. $\left[{ }^{11} \mathrm{C}\right] \mathrm{KD} 2$ is a very promising radiotracer for $\mathrm{CB} 2$, but with good potential for improvement towards reduced protein binding. The syntheses of KD2 derivatives with improved physicochemical properties are currently ongoing in our laboratory.

\section{Acknowledgment}

R. S. would like to thank the Swiss Chemical Society and DSM Nutritional Products AG for the award. The authors greatly acknowledge Mr. Bruno Mancosu and Mrs. Claudia Keller for their technical assistance.

Received: January 17, 2014
[1] S. D. Skaper, A. Buriani, R. Dal Toso, L. Petrelli, S. Romanello S, L. Facci, A. Leon, Proc. Natl. Acad. Sci. USA 1996, 93, 3984.

[2] J. C. Ashton, M. Glass, Curr. Neuropharmacol. 2007, $5,73$.

[3] C. Benito, E. Nunez, M. R. Pazos, R. M. Tolon, J. Romero, Mol. Neurobiol. 2007, 36, 75.

[4] C. Benito, J. P. Romero, R. M. Tolon, D. Clemente, F. Docagne, C. J. Hillard, C. Guaza, J. Romero, J. Neurosci. 2007, 27, 2396.

[5] S. H. Ramirez, J. Hasko, A. Skuba, S. Fan, H. Dykstra, R. McCormick, N. Reichenbach, I. Krizbai, A. Mahadevan, M. Zhang, R. Tuma, Y. J. Son, Y. Persidsky, J. Neurosci. 2012, 32, 4004.

[6] J. Palazuelos, N. Davoust, B. Julien, E. Hatterer, T. Aguado, R. Mechoulam, C. Benito, J. Romero, A. Silva, M. Guzmán, S. Nataf, I. Galve-Roperh, J. Biol. Chem. 2008, 283, 13320.

[7] J. Fernandez-Ruiz, J. Romero, G. Velasco, R. M. Tolon, J. A. Ramos, M. Guzman, Trends Pharmacol. Sci. 2007, 28, 39.

[8] J. L. Shoemaker, K. A. Seely, R. L. Reed, J. P. Crow, P. L. Prather, J. Neurochem. 2007, 101, 87.

[9] N. Evens, G. M. Bormans, Curr. Top. Med. Chem. 2010, 10, 1527.

[10] S. Pasquini, M. De Rosa, V. Pedani, C. Mugnaini, F. Guida, L. Luongo, M. De Chiaro, S. Maione, S. Dragoni, M. Frosini, A. Ligresti, V. Di Marzo, F. Corelli, J. Med. Chem. 2011, $54,5444$.

[11] N. Turkman, A. Shavrin, R. A. Ivanov, B. Rabinovich, A. Volgin, J. G. Gelovani, M. M. Alauddin, Bioorg. Med. Chem. 2011, 19, 5698.

[12] M. D. Van Sickle, M. Duncan, P. J. Kingsley, A Mouihate, P. Urbani, K. Mackie K, N. Stella, A. Makriyannis, D. Piomelli, J. S. Davison, L. J. Marnett, V. Di Marzo, Q. J. Pittman, K. D. Patel, K. A. Sharkey, Science 2005, 310, 329.

[13] G. A. Cabral, F. Marciano-Cabral, J. Leukoc. Biol. 2005, 78, 1192.

[14] N. Stella, Glia 2010, 58, 1017.

[15] A. A. Wilson, L. Jin, A. Garcia, J. N. DaSilva, S. Houle, Appl. Radiat. Isot. 2001, 54, 203.

[16] S. Rossi, G. Bernardi, D. Centonze, Exp. Neurol. 2010, 224, 92.

[17] E. S. Onaivi, Int. Rev. Neurobiol. 2009, 88, 335.

[18] J. P. Gong, E. S. Onaivi, H. Ishiguro, Q. R. Liu, P. A. Tagliaferro, A. Brusco, G. R. Uhl, Brain Res. 2006, 1071, 10.

[19] L. Qin, X. Wu, M. L. Block, Y. Liu, G. R. Breese, J. S. Hong, D. J. Knapp, F. T. Crews, Glia 2007, 55, 453.

[20] A. G. Horti, Y. Gao, H. T. Ravert, P. Finley, H. Valentine, D. F. Wong, C. J. Endres, A. V. Savonenko, R. F. Dannals, Bioorg. Med. Chem. 2010, 18,5202 . 